\title{
Flora da Bahia: Caryocaraceae
}

\author{
Ricardo de Oliveira Perdiz ${ }^{1,2^{*}}$, Wallace Messias Barbosa São-Mateus ${ }^{3}$ \& André Márcio Amorim ${ }^{1,2,4}$
}

${ }^{1}$ Herbário André Maurício V. de Carvalho (CEPEC), Km 22, Rodovia Ilhéus-Itabuna, 45650-970, Ilhéus, Bahia, Brasil.

${ }^{2}$ Programa de Pós-graduação em Botânica, Departamento de Ciências Biológicas, Universidade Estadual de Feira de Santana, Av. Transnordestina s/n, Novo Horizonte, 44036-900, Feira de Santana, Bahia, Brasil.

${ }^{3}$ Programa de Pós-graduação em Sistemática e Evolução, Centro de Biociências, Universidade Federal do Rio Grande do Norte, Av. João Medeiros, Campus Universitário Lagoa Nova, 59072-970, Natal, Rio Grande do Norte, Brasil.

${ }^{4}$ Departamento de Ciências Biológicas, Universidade Estadual de Santa Cruz, Km 16, Rodovia Ilhéus-Itabuna, 45662-900, Ilhéus, Bahia, Brasil.

Resumo - É apresentado o levantamento florístico de Caryocaraceae no estado da Bahia, Brasil. Foram reconhecidas quatro espécies distribuídas em dois gêneros: Anthodiscus amazonicus, Caryocar brasiliense, C. coriaceum e C. edule. É apresentada uma chave de identificação, descrições e comentários taxonômicos para os gêneros e espécies, além de ilustrações e mapas de distribuição geográfica das espécies na Bahia.

Palavras-chave adicionais: Anthodiscus, Brasil, Caryocar, florística, taxonomia.

Abstract (Flora of Bahia: Caryocaraceae) - The floristic survey of the Caryocaraceae from Bahia State, Brazil, is presented. Two genera and four species were recognized: Anthodiscus amazonicus, Caryocar brasiliense, C. coriaceum, and C. edule. An identification key, descriptions and taxonomic notes for genera and species are given, in addition to illustrations and maps of species distribution in Bahia.

Additional key words: Anthodiscus, Brazil, Caryocar, floristics, taxonomy.

\section{Caryocaraceae}

Árvores, raramente subarbustos ou arbustos. Folhas alternas ou opostas, trifolioladas, com pecíolo alongado; folíolos membranáceos, cartáceos ou coriáceos, os laterais assimétricos, lâmina elíptica, oblonga a levemente ovada ou obovada, margem crenada, serreada ou denteada, raramente inteira, domácias em forma de tufos de tricomas presentes (Caryocar) ou não (Anthodiscus); estípulas decíduas ou ausentes, estipelas $2-4$, frequentemente presentes. Inflorescência em racemo terminal. Flores bissexuadas, diclamídeas, actinomorfas; sépalas 5(6), prefloração imbricada, conatas, margem denteada, cupuliformes (Anthodiscus) ou ovadas (Caryocar); pétalas 5(6), prefloração imbricada, livres ou conatas na base ou no ápice formando uma caliptra; estames 55-750, caducos, adnatos às pétalas, filetes geralmente unidos na base em forma de um anel, frequentemente tuberculados no ápice, anteras rimosas; ovário súpero, 4(-6)-locular (Caryocar) ou 8-12(-15)-locular (Anthodiscus), estiletes simples (Caryocar) ou compostos (Anthodiscus), filiformes, óvulos 1 por lóculo, basais, eretos, anátropos ou ortótropos. Fruto drupa, globoso a subgloboso, mesocarpo carnoso, endocarpo rígido e lenhoso, com superfície externa muricada, tuberculada ou espinulosa, que se divide em pirenos unisseminados, sementes 1-4 (Caryocar) ou 8-12 (Anthodiscus), frequentemente reniformes, endosperma escasso ou ausente.

Caryocaraceae possui distribuição neotropical e compreende os gêneros Anthodiscus e Caryocar, com nove

"Autor para correspondência: ricoperdiz@gmail.com

Editor responsável: Pedro Fiaschi

Submetido em: 24 maio 2011; publicação eletrônica: 7 jun. 2012 e 16 espécies, respectivamente (Prance 1998). A maioria das espécies ocorre no domínio Amazônico (Prance \& Silva 1973), com registro de 16 espécies no Brasil (Prance \& Medeiros 2010); das quais, quatro são encontradas na Bahia.

\section{Chave de identificação}

1. Folhas alternas, ausência de domácias nos folíolos; sépalas cupuliformes, reduzidas (2-3 $\mathrm{mm}$ compr.); ovário 8-12(-15)-locular, estiletes 8-12(-15); fruto com 8-12 sementes............ 1. Anthodiscus amazonicus

1'. Folhas opostas, presença de domácias nos folíolos; sépalas ovadas, grandes (5-9 mm compr.); ovário 4(-6)locular, estiletes 4; fruto com 1-4 sementes.....

2. Caryocar

2. Estipelas presentes; folíolos com o ápice acuminado ou agudo, margem serreada. Ocorrência restrita ao domínio Atlântico. 2.3. C. edule

2'. Estipelas ausentes; folíolos com o ápice retuso a arredondado ou agudo, margem crenada. Ocorrência no domínio Cerrado.

3. Folíolo terminal 10,5-11,3 cm compr., lâminas tomentosas a vilosas, veias secundárias a quaternárias salientes na face abaxial e impressas na adaxial, rede de venação conspícua nas duas faces, domácias incospícuas

2.1. C. brasiliense

3'. Folíolo terminal 6-10 cm compr., lâminas glabras, veias secundárias salientes na face abaxial, rede de venação inconspícua nas duas faces, domácias conspícuas.... 2.2.C. coriaceum

Sitientibus série Ciências Biológicas 12(1): 109-113. 2012. 
1. Anthodiscus G.Mey., Prim. Fl. Esseq.: 193. 1818.

Árvores ou arbustos; ramos glabros, não lenticelados. Folhas alternas, folíolos coriáceos ou cartáceos, margem crenada ou inteira, domácias, estípulas e estipelas ausentes. Flores em racemos terminais, 6,5-8,5 cm compr.; sépalas 5, cupuliformes, reduzidas (2-3 $\mathrm{mm}$ compr.); pétalas 5, conatas no ápice formando uma caliptra; estames 100-280, fundidos na base formando um pequeno tubo, filetes longos, conatos na base das pétalas; ovário 8-12(-15)-locular, estiletes 8-12(-15). Fruto drupa subglobosa, ligeiramente discoide, com a maioria dos lóculos desenvolvidos, pericarpo lenhoso, liso, não muricado; sementes pequenas (ca. $4 \mathrm{~mm}$ compr.), lateralmente compressas, 8-15 por fruto; embrião com radícula espiralada.

Anthodiscus possui nove espécies e distribuição exclusivamente neotropical, ocorrendo no Brasil, Colômbia, Costa Rica, Guiana Francesa, Peru, Suriname e Venezuela (Prance 1998). No território brasileiro, são referidas cinco espécies (Prance \& Medeiros 2010), uma delas encontrada na Bahia.

\subsection{Anthodiscus amazonicus Gleason \& A.C. Sm.,} Brittonia 2: 156. 1936.

Nome popular: pequi-mirindiba (Mattos Silva 1809).

Figuras $1 \mathrm{~A}-\mathrm{C}$ e 2.

Árvores 5-25 m alt., ramos glabrescentes. Folhas com pecíolo glabro, 1,5-4 cm compr., peciólulo terminal 4-10 $\mathrm{mm}$ compr., peciólulos laterais $2-7 \mathrm{~mm}$ compr.; folíolos coriáceos, glabrescentes, folíolo terminal 5,5-8,5 × 2,3-4 $\mathrm{cm}$, os laterais $4,5-8,5 \times 2,3-3,4 \mathrm{~cm}$, lâmina oblongoelíptica, base cuneada, ápice retuso a cuspidado, margem crenada. Inflorescências com raque cilíndrica, glabra, 6,5-8,5 cm compr.; racemo com 14-22 flores; pedicelo canaliculado, glabrescente, 1-2 cm compr.; bractéolas caducas. Flores com sépalas verdes, $2-3 \times 1,5-2 \mathrm{~mm}$; pétalas amarelas, obovadas, $5-8 \times 2-3,5 \mathrm{~mm}$; estames ca. 170 , ca. $5 \mathrm{~mm}$ compr., filetes e anteras amarelas; ovário globoso, glabro, estiletes ca. $1,5-3 \mathrm{~mm}$ compr., glabrescentes. Fruto ligeiramente discoide, $1-1,6 \mathrm{~cm} \times$ 2-2,5 cm, glabro, amarelo na maturidade.

Anthodiscus amazonicus é encontrada no Brasil e Colômbia. No Brasil, ocorre nos estados do Acre, Amazonas, Bahia, Pará e Rondônia (Prance \& Medeiros 2010). H8, I8: florestas ombrófilas densas sobre tabuleiros na região sul e extremo sul do estado. Floresce entre janeiro e julho, frutifica de janeiro a junho.

Material selecionado - Belmonte, Estação Experimental Gregório Bondar (EGREB), $16^{\circ} 08^{\prime} \mathrm{S}, 39^{\circ} 15^{\prime} \mathrm{W}, 12$ jan. 1985 (fl., fr.), L.A. Mattos Silva et al. 1809 (CEPEC, RB); Porto Seguro, RPPN Estação Veracel, 16 $6^{\circ} 30^{\prime} \mathrm{S}, 39^{\circ} 15^{\prime} \mathrm{W}, 100 \mathrm{~m}, 9$ jul. 2010 (fl.), G.M. Carvalho et al. 394 (CEPEC); Santa Cruz Cabrália, estrada velha para Santa Cruz Cabrália, entre a Estação Ecológica PauBrasil e Santa Cruz Cabrália, 162ㄱ'S, 39¹5'W, 5 abr. 1979 (bot., fr.), S. Mori \& T.S. Santos 11660 (CEPEC, RB); Una, Reserva Biológica de Una (REBIO-UNA), $15^{\circ} 09^{\prime} \mathrm{S}, 39^{\circ} 05^{\prime} \mathrm{W}, 14-15 \mathrm{abr}$. 1993 (fr.), A. Amorim et al. 1241 (CEPEC, HUEFS).

Anthodiscus amazonicus se diferencia das espécies de Caryocar por apresentar folhas alternas, sépalas cupuliformes e reduzidas (2-3 $\mathrm{mm}$ compr.) e frutos ligeiramente discoides, com 8-12 sementes. Representa um exemplo de disjunção entre os domínios Atlântico e Amazônico (Prance \& Mori 1980).

\section{Caryocar L.}

Árvores, raramente subarbustos ou arbustos; ramos glabros ou tomentosos, lenticelados. Folhas opostas, folíolos coriáceos ou membranáceos, margem crenada, denteada ou raro inteira, domácias presentes, estípulas caducas ou persistentes, estipelas frequentemente presentes. Flores em racemos terminais, $10-10,5 \mathrm{~cm}$ compr.; sépalas 5(6), ovadas e grandes (5-9 $\mathrm{mm}$ compr.); pétalas 5(6), conatas na base; estames numerosos (mais que 100 ), fundidos na base formando um pequeno tubo; filetes longos, adnatos na base das pétalas; ovário 4(-6) locular, estiletes 4(-6). Fruto com 1-4 lóculos desenvolvidos, mesocarpo espesso, carnoso, endocarpo lenhoso, muricado, tuberculado ou espinescente na superfície externa; sementes grandes (mais que $2 \mathrm{~cm}$ compr.), reniformes, $1-4$ por fruto; embrião com radícula reta a arqueada.

Caryocar possui 16 espécies com distribuição exclusivamente Neotropical (Prance 1998). Ocorre na Bolívia, Brasil, Colômbia, Costa Rica, Equador, Guiana Francesa, Paraguai, Peru, Suriname e Venezuela (Prance 1998). No Brasil, ocorrem 12 espécies (Prance \& Medeiros 2010), das quais três são registradas na Bahia. Prance \& Medeiros (2010) citam C. cuneatum Wittm. com suposta ocorrência na Bahia. Coleções desta espécie, no entanto, não foram detectadas no estado.

2.1. Caryocar brasiliense Cambess. in A.St.-Hil., Fl. Bras. Mer. 1: 322; tab. 67. bis. 1828.

Nome popular: pequi.

Figuras 1D-H e 2.

Árvores 2-7(-15) m alt.; ramos tortuosos, glabrescentes. Folhas com estípulas caducas, estipelas ausentes; pecíolo 3,1-6,6 cm compr., tomentoso, peciólulo terminal 5-6 mm compr., os laterais $2-3 \mathrm{~mm}$ compr.; folíolos coriáceos, tomentosos a vilosos nas duas faces, mais intensamente nas veias primárias e secundárias, esparsos na face adaxial, folíolo terminal 10,5-11,3 $\times$ 7,6-8,6 cm, os laterais 7,2-10,2 × 7,6-8,6 cm, lâmina elíptica a levemente ovada ou obovada, base aguda a arredondada no folíolo terminal e oblíqua nos laterais, margem crenada, ápice obtuso a arredondado ou agudo, veias secundárias a quaternárias salientes na face abaxial $\mathrm{e}$ impressas na adaxial, rede de venação conspícua em ambas as faces, domácias inconspícuas na face abaxial. Inflorescências com raque quadrangular, sulcada, tomentosa, 10-15 cm compr.; racemo com 18-20 flores; pedicelo canaliculado, tomentoso, $3-3,3 \mathrm{~cm}$ compr. nas flores proximais, ca. $1,9 \mathrm{~cm}$ compr. nas flores distais; bractéolas 2-4×2-3 mm. Flores com sépalas verdes, $5-7 \times$ 6-7 $\mathrm{mm}$; pétalas amarelo-esverdeadas, oblongas, $18-30 \times$ 5-15 mm; estames mais de 250, 4,5-5 cm compr., filetes de cor creme, anteras amarelas; ovário globoso, glabro, estiletes 4-5 cm compr., glabros. Fruto globoso, 4,5-7 × 4-7 cm, glabro, amarelo quando maduro; sementes 1-2.

Caryocar brasiliense é encontrada na Bolívia, Brasil e Paraguai. No Brasil, ocorre nas Regiões Centro-Oeste, 

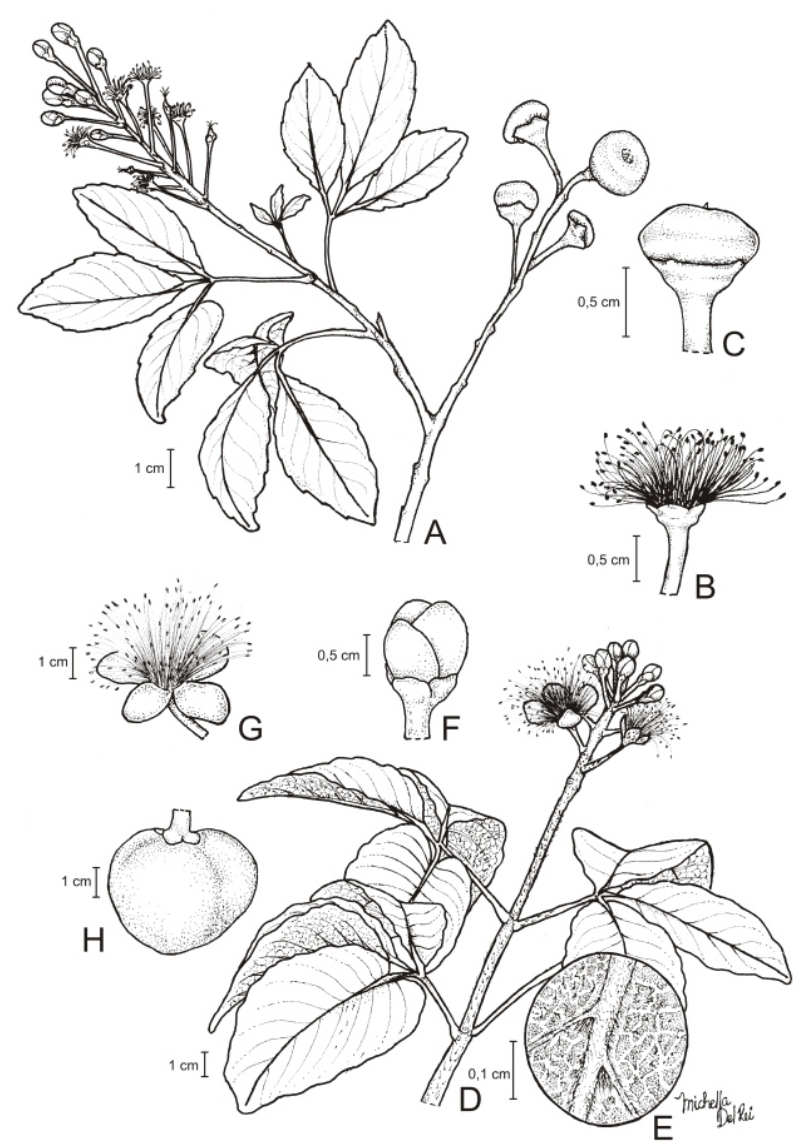

Figura 1. A-C. Anthodiscus amazonicus: A- ramo com botões, flores e frutos; B- flor, pétalas removidas; C- fruto; D-H. Caryocar brasiliense: D- ramo com botões e flores; E- detalhe da face abaxial do folíolo, evidenciando as domácias; F- botão floral; G- flor; H- fruto. (A-B-Mori 11863; C-Sant'Ana 878; D-E, G- Harley 27701; F- Mori 16855; HCorreia 74).

Norte, Sudeste e Sul (apenas no Paraná) (Prance \& Medeiros 2010). D2, E2, F3, F5, G3, G4, G6: regiões oeste e central, no domínio Cerrado (Figura 4). Coletada com flores em abril, julho, agosto e de outubro a dezembro; frutos em fevereiro, abril e de outubro a dezembro.

Material selecionado - Brumado, $5 \mathrm{~km}$ antes de Brumado,

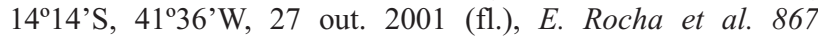
(HUESC); Caetité, $3 \mathrm{~km}$ de Brejinho das Ametistas, $14^{\circ} 15^{\prime} \mathrm{S}$, $42^{\circ} 31^{\prime} \mathrm{W}, 1100 \mathrm{~m}, 29$ abr. 2001 (fl.), C. Correia et al. 74 (CEPEC, HUEFS); Cariranha, Médio São Francisco, a $1 \mathrm{~km}$ do rio

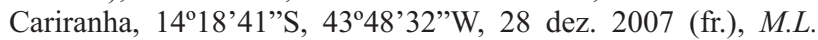

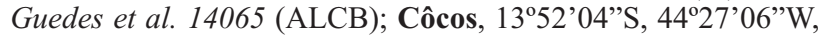
29 ago. 2007 (fl.), M.L. Guedes et al. 13704 (ALCB, HUEFS); Cordeiros, próximo ao rio, 156'23"S, 41 52 '33”'W, 15 nov. 1979 (bot., fr.), A.P. Araujo 168 (CEPEC, HRB, RB); Correntina, $5 \mathrm{~km}$ from Correntina on the road to Posse, $13^{\circ} 23^{\prime} \mathrm{S}, 44^{\circ} 41^{\prime} \mathrm{W}, 630 \mathrm{~m}, 24$ jul. 1998 (est.), J.A. Ratter et al. 8019 (HUEFS); Feira da Mata, Médio São Francisco, próximo ao rio Cariranha, 141' $54^{\prime}$ 'S,

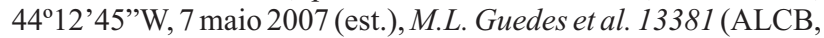
HUEFS); Rio de Contas, fazenda Vacaria, $13^{\circ} 49^{\prime} \mathrm{S}, 42^{\circ} 24^{\prime} \mathrm{W}, 8$ maio 2004 (est.), R.M. Castro \& F.H.F. Nascimento 1014 (HUEFS).

Caryocar brasiliense é reconhecida por apresentar folíolos tomentosos a vilosos nas duas faces, com ápice obtuso a arredondado ou agudo e veias secundárias a quaternárias salientes na face abaxial e impressas na adaxial, além da rede de venação ser conspícua em ambas as faces. É simpátrica com C. coriaceum, de quem se diferencia basicamente por apresentar folíolos pilosos (vs. folíolos glabros) nas duas faces. O mesocarpo de $C$. brasiliense é utilizado na alimentação e como fonte de óleo (Prance 1990).

\subsection{Caryocar coriaceum Wittm. in Mart., Eichl. \& Urban,} Fl. Bras. 12(1): 352. 1886.

Nomes populares: piqui-preto (Mori 12321).

Figuras $3 \mathrm{~A}-\mathrm{C}$ e 4.

Árvores 4,5-12 m alt.; ramos eretos, glabros. Folhas com estípulas caducas, estipelas ausentes, pecíolo 3,1-4,5 cm compr., glabro, peciólulo terminal $4-5 \mathrm{~mm}$ compr., os laterais ca. $3 \mathrm{~mm}$ compr.; folíolos coriáceos, glabros, o terminal 6-10 × 4,3-6,4 cm, os laterais 5,5-10 × 4,2-6,5 $\mathrm{cm}$, lâmina obovada ou ligeiramente elíptica, base aguda a cuneada no folíolo terminal e oblíqua nos laterais, margem crenada, ápice retuso ou agudo, veias secundárias salientes na face abaxial, rede de venação inconspícua em ambas as faces, domácias conspícuas. Inflorescências com raque subcilíndrica a quadrangular, estriada a sulcada, glabra, 6-13 cm compr.; racemo com 15-20 flores; pedicelo canaliculado, glabro, 1,7-3,3 cm compr., bractéolas caducas. Flores com sépalas verdes, $8-9 \times 2-4 \mathrm{~mm}$; pétalas amarelas, arredondadas, 2-2,5 × 1,5-2 cm; estames ca. 300, 3-3,8 cm compr., filetes creme, anteras amarelas; ovário globoso, glabro, estiletes ca. $4 \mathrm{~mm}$ compr., glabros. Fruto globoso, 4,2-6 $\times 3,5-5 \mathrm{~cm}$, glabro, unisseminado.

Caryocar coriaceum ocorre somente no Brasil, com registro nos estados da Bahia e Ceará (Prance \& Medeiros 2010). C2, D2, D4, D6, E3, F5, G5, H6: regiões central, norte e noroeste do estado, no domínio Cerrado (Figura 4). Coletada com flores de maio a novembro; frutos em

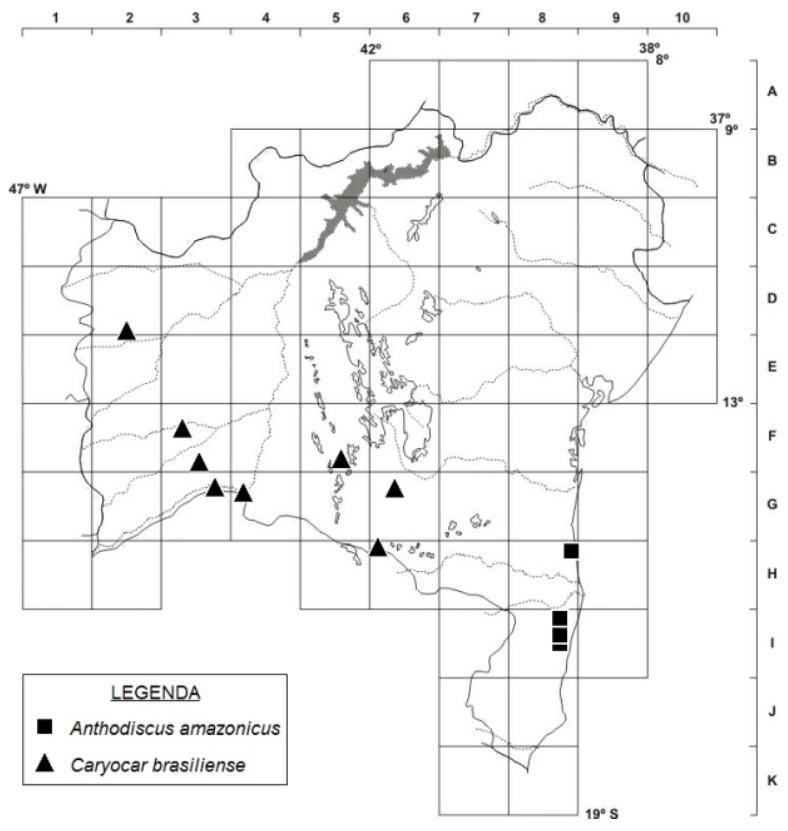

Figura 2. Distribuição geográfica de Anthodiscus amazonicus e Caryocar brasiliense no estado da Bahia. 
fevereiro e novembro.

Material selecionado - Barra, Fazenda do Brejo, $11^{\circ} 05^{\prime} \mathrm{S}$, $43^{\circ} 08^{\prime}$ W, 16 nov. 2007 (fr.), M.L. Guedes et al. 13926 (ALCB); Barreiras, cachoeira Acaba-Vida, ca. $91 \mathrm{~km}$ da sede, 11 ${ }^{\circ} 53^{\prime}$ '41'S, 45³6'03"'W, 710 m, 4 fev. 2000 (fr.), L.C.L. Lima et al. 23 (HUEFS); Caetité, ca. $15 \mathrm{~km}$ a oeste de Caetité, 1359'34"S, 42³4'22'W, 975-1000 m, 28 ago. 1999 (bot.), E. Melo et al. 2883

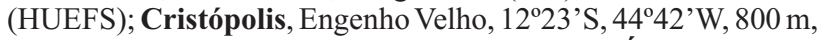
13 jul. 1979 (fl.), G. Hatschbach 42310 (CEPEC); Érico Cardoso, Vereda, estrada Morro do Fogo, 14¹1'04"S, 42³0'10"W, 1093 m, s.d. (fr.), T. Ribeiro et al. 313 (ALCB, CEPEC, HRB, HUEFS); Formosa do Rio Preto, $17 \mathrm{~km}$ de Formosa, depois do

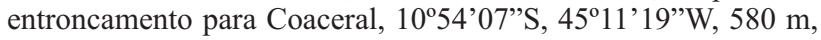
28 mar. 2000 (est.), R. Harley et al. 53726 (HUEFS); Morro do Chapéu, jardim da cidade, em frente à CPRM, $11^{\circ} 04^{\prime} \mathrm{S}, 41^{\circ} 10^{\prime} \mathrm{W}$, 1000 m, 2 maio 2003 (fl.), J. Carvalho-Sobrinho 121 (HUEFS); Rio de Contas, rodovia Livramento do Brumado/Rio de Contas, 1506'23"S, 41 '52'33”'W, 1.000 m, 19-20 jul. 1979 (fl.), S.A. Mori etal. 12321 (CEPEC).

Caryocar coriaceum pode ser reconhecida por apresentar ramos eretos e glabros e folíolos de lâmina glabra, com exceção das domácias conspícuas na face abaxial. Assim como C. brasiliense, C. coriaceum também possui o mesocarpo comestível (Prance 1990).

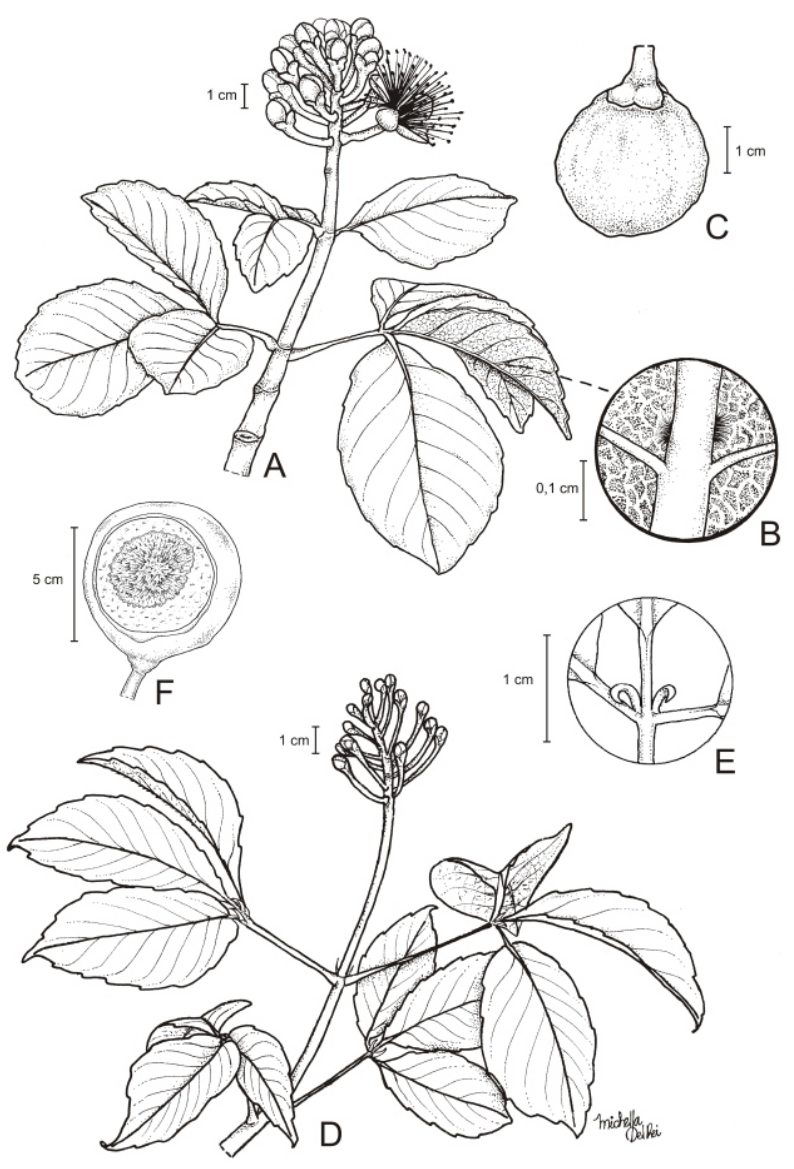

Figura 3.A-C. Caryocar coriaceum: A-ramo com flores e flores; B-detalhe da face abaxial do folíolo, evidenciando as domácias; C- fruto; D-F. $C$. edule: D- ramo com botões florais; E- estipelas; $\mathbf{F}$ - fruto em corte longitudinal evidenciando o pireno espinescente. (A-B- Mori 12321; CRibeiro 313; D-Santos 302; E-F- Carvalho 307).

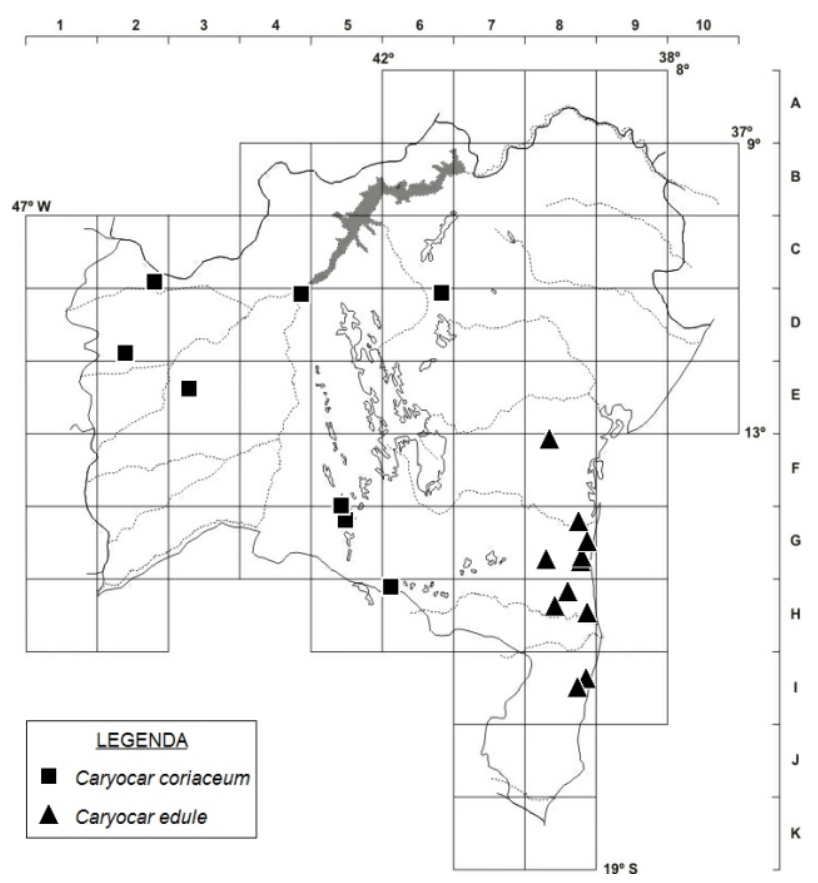

Figura 4. Distribuição geográfica de Caryocar coriaceum e C. edule no estado da Bahia.

2.3. Caryocar edule Casar., Nov. Strip. Bras. Decad. 8: 67. 1844.

Nomes populares: pequi-preto (Mattos Silva 4022).

Figuras 3D-F e 4.

Árvores 10-40 m alt.; ramos eretos, glabrescentes. Folhas com estípulas caducas, estipelas 4, duas mais largas, infladas e recurvadas, pecíolo 3,9-9,4 cm compr., glabrescente, peciólulo terminal 10-11 mm compr., os laterais 3-8 mm compr.; folíolos membranáceos, folíolos jovens com face abaxial arroxeada, glabrescentes, folíolo terminal $13,5-17 \times 4-8,3 \mathrm{~cm}$, os laterais $6,3-15,6 \times 3,5-8,3$ $\mathrm{cm}$, lâmina elíptica, base cuneada no folíolo terminal, oblíqua nos laterais, margem serreada, ápice acuminado ou agudo, veias secundárias salientes na face abaxial, rede de venação conspícua apenas na face abaxial, domácias conspícuas na face abaxial. Inflorescências com raque cilíndrica, estriada, glabrescente, ca. $10,5 \mathrm{~cm}$ compr.; racemo com 20-30 flores; pedicelo canaliculado, glabrescente, 1,5-3,3 cm compr., bractéolas caducas. Flores com sépalas verdes, 5-9 × 1,5-3 mm, pétalas amarelas, oblongas a obovada, 2,5-3 × 1-1,5 cm; estames 110-130, 4-4,5 cm compr., filetes e anteras amarelos; ovário globoso, glabro, estiletes ca. $4 \mathrm{~cm}$ compr., glabros. Fruto globoso, 7-9 × 6-7 cm, glabro, amarelo quando maduro; semente 1.

Caryocar edule é encontrada nos estados da Bahia, Minas Gerais e Rio de Janeiro, ocorrendo apenas no domínio Atlântico (Lombardi \& Gonçalves 2000; Prance \& Medeiros 2010). Através de coleções de herbário (Romão 1291 e Folli 1293, CVRD), sua presença se confirma também no estado do Espírito Santo. F8, G8, H8, I8: no litoral, em florestas ombrófilas densas sobre tabuleiros e em formações montanhosas, até ca. $900 \mathrm{~m}$ de altitude (Figura 
4). Floresce de dezembro a janeiro e frutifica em março e agosto.

Material selecionado - Almadina, fazenda Cruzeiro do Sul, Serra do Sete-Paus, 1444'06”S, 3941'46”W, 21 jan. 1998 (est.), J.G. Jardim et al. 1372 (CEPEC); Amargosa, Serra do Timbó, $13^{\circ} 05^{\prime}$ 'S, 39³9'W, 750-900 m, 27 jan. 2007 (fl.), D. Cardoso et al. 1654 (CEPEC, HUEFS); Arataca, Serra das Lontras, 15¹1'22”'S, 39²3'7'W, 13 set. 2009 (est.), A.M. Amorim et al. 7921 (CEPEC); Barro Preto, Serra da Pedra Lascada, 1446'13"S, 39¹2'10"W, 600-900 m, 13 dez. 2004 (fl.), A.M. Amorim et al. 4544 (CEPEC); Camacan, RPPN Serra Bonita, 15²3'30'S, 39³3'55'W, 835 m, 31 ago. 2008 (est.), A.M. Amorim et al. 7706 (CEPEC); Ilhéus, fazenda Santa Maria, 14\%42'25”S, 39¹1'23”W, 26 mar. 2001 (est.), R.H.R. Sambuichi et al. 348 (HUESC); Ituberá, 1373'S, $39^{\circ} 14$ 'W, 25 jan. 2006 (fl.), R.M. Valadão et al. 707 (ALCB); Porto Seguro, RPPN Estação Veracel, 16³0'S, 39² $15^{\prime} \mathrm{W}, 100 \mathrm{~m}, 15$ mar. 2010 (fr.), G.M. Carvalho et al. 307 (CEPEC); Santa Cruz Cabrália, área da Estação Ecológica do Pau-Brasil (ESPAB), 16²16'S, 3901'W, 19 jan. 1984 (est.), F.S. Santos et al. 195 (CEPEC); Una, fazenda São Rafael, 15²9'S, 3907'W, 12 dez.
1968 (est.), T.S. Santos et al. 302 (CEPEC); Uruçuca, Parque Estadual Serra do Conduru, $14^{\circ} 29^{\prime}$ 'S, 3906'W, 19 ago. 2008 (est.), A.M. Amorim et al. 7677 (CEPEC).

Caryocar edule pode ser diferenciada das outras espécies do gênero no estado da Bahia por apresentar quatro estipelas, duas destas mais largas, infladas e recurvadas. Os folíolos são membranáceos e possuem a face abaxial arroxeada nos folíolos jovens. Trata-se de uma espécie pouco coletada devido ao grande porte dos indivíduos adultos, que podem chegar a cerca de $40 \mathrm{~m}$ de altura. $\mathrm{O}$ mesocarpo é comestível (Prance 1990).

\section{Agradecimentos}

Os autores agradecem Michella Del Rei Teixeira pelas ilustrações. AMA é financiado pelo CNPq (bolsa PQ 309303/2009-5; Reflora 563548/2010-0).

\section{REFERÊNCIAS}

Lombardi, J.A. \& Gonçalves, M. 2000. Composição florística de dois remanescentes de Mata Atlântica do sudeste de Minas Gerais, Brasil. Revista Brasileira de Botânica 23(3): 255-282.

Prance, G.T. 1990. The genus Caryocar L. (Caryocaraceae): an underexploited tropical resource. In: G.T. Smith \& M.J. Balick (eds), New directions in the study of plants and people: research contributions from the Institute of Economic Botany. Advances in Economic Botany 8: 177-188.

Prance, G.T. 1998. Caryocaraceae. In: P.E. Berry, B.K. Holst \& K. Yatskievych (eds), Flora of the Venezuelan Guayana. Vol. 4. Missouri Botanical Garden Press, St. Louis, p. 164-170.

Prance, G.T. \& Medeiros, H. 2010. Caryocaraceae. In: R.C.
Forzza, J.F.A. Baumgratz, C.E.M. Bicudo, A.A. Carvalho Jr, A. Costa, D.P. Costa, M. Hopkins, P.M. Leitman, L.G. Lohmann, L.C. Maia, G. Martinelli, M. Menezes, M.P. Morim, M.A.N. Coelho, A.L. Peixoto, J.R. Pirani, J. Prado, L.P. Queiroz, V.C. Souza, J.R. Stehmann, L.S. Sylvestre, B.M.T. Walter \& D. Zappi (eds), Catálogo de Plantas e Fungos do Brasil. Vol. 1. Instituto de Pesquisas Jardim Botânico do Rio de Janeiro, Rio de Janeiro, p. 839-840.

Prance, G.T. \& Mori., S.A. 1980. Anthodiscus (Caryocaraceae), um gênero disjunto entre a Amazônia e o leste do Brasil. Revista Brasileira de Botânica 3: 63-65.

Prance, G.T. \& Silva, M.F. 1973. A monograph of the Caryocaraceae. Flora Neotropica Monograph 12: 1-75.

\section{Lista de Exsicatas}

Anjos, A.B. 2 (2.1); Amorim, A.M. 1241, 1909 (1.1), 4544, 7677, 7706, 7921 (2.3); Araújo, A.P. 168 (2.1); Atkins, S. PCD 4923 (2.1); Borgo, M. 1473 (2.1); Brito, D.S. 83 (2.1); Cardoso, D. 1654 (2.3); Carvalho, A.M. 3704 (2.1), 4009 (2.2); Carvalho, G.M. 307 (2.3), 394 (1.1); Carvalho-Sobrinho, J.G. 121 (2.2); Castro, R.M. 1014 (2.1); Correia, C. 74 (2.1); Filho, L.C.O. 71 (2.1); Folli, D.A. 1293 (2.3); Fonseca, M.L. 4100 (2.1); Fróes, R.L. 23792 (1.1); Guedes, M.L. 13324, 13381, 13704 (2.1), 13926 (2.2), 14065 (2.1); Harley, R. 21356, 27701 (2.1), 53726 (2.2); Hatschbach, G. 42310 (2.2), 79283 (2.1); Hind, N. PCD 4253 (2.1); Jardim, J.G. 11 (1.1), 1372 (2.3), 3628 (2.1); J. S. 11
(2.3); Lima, L.C.L. 23 (2.2); Mattos Silva, L.A. 57 (2.1), 1809 (1.1), 4021, 4022 (2.3); Melo, E. 2580 (2.1), 2883 (2.2); Mendonça, R.C. 4461 (2.1); Mori, S.A. 11660, 11863 (1.1), 12321 (2.2), 16855 (2.1); Nascimento, F.H.F. 77 (2.1); Pacheco, L.M. 52 (2.3); Pastore, U. 124 (2.1); Queiroz, L.P. 2040, 2125 (2.2), 3589 (2.1); Ratter, J.A. 8019 (2.1); Ribeiro, T. 313 (2.2); Rocha, E.A. 867 (2.1); Romão, G. 1291 (2.3); Rylands, A. 158 (2.3); Sambuichi, R.H.R. 213, 348 (2.3); Sant'Ana, S.C. 878 (1.1); Santos, F.S. 195 (2.3); Santos, T.S. 302 (2.3); Valadão, R.M. 623 (2.1), 707 (2.3). 